\title{
Pediatric COVID-19 Associated Rhabdomyolysis
}

\author{
(D) Parisa Armanpoor1, (1) Parvaneh Armanpoor2 \\ ${ }^{1}$ Gonabad University of Medical Science, Department of Pediatrics, Gonabad, Iran \\ 2Mashhad University of Medical Science, Department of Radiology, Mashhad, Iran
}

\begin{abstract}
The incidence of rhabdomyolysis secondary to various causes has been reported, especially for viral infections such as influenzas. It is well established that Coronavirus disease-2019 (COVID-19) can include a large array of symptoms during the disease course, but there have been few reports of COVID-19-related rhabdomyolysis. We report a 10-year-old boy who presented with fever, some dry cough, myalgias, and painful walking. His COVID-19 polymerase chain reaction test performed through the nasopharyngeal swab was positive. His first creatinine kinase level was $8,000 \mathrm{U} / \mathrm{L}$. He was treated with isotonic intravenous fluids because of rhabdomyolysis. Muscle weakness and pain are common symptoms of the 2019 novel COVID, but physicians should be aware of the possibility of rhabdomyolysis, especially when patients complain of local pain and weakness in their muscles. Pediatric clinicians should be aware of this complication related to the novel 2019 coronavirus. Timely diagnosis and proper treatment improve the patient's prognosis.
\end{abstract}

Keywords: COVID-19, rhabdomyolysis, pediatric

\section{Introduction}

Coronavirus disease-2019 (COVID-19) is a worldwide health concern affecting people of all ages. The prevalent symptoms of COVID-19 are fever, dry cough, tiredness, and muscle pain; while headache, conjunctivitis, and diarrhea are less common. There have been few reports of COVID19 -related rhabdomyolysis in adults $(0.2 \%$ of 1,099 patients in China) (1) and fewer in children (2). Rhabdomyolysis is defined as muscle necrosis that presents with muscle weakness, myalgia, and sometimes dark urine. Herein, we report a case of rhabdomyolysis in a patient diagnosed with COVID-19.

\section{Case Report}

A 10-year-old boy, previously healthy, initially presented to the pediatric urgent care unit with 2 days of fever and some dry cough and acute muscle weakness and pain of both lower limbs. He was unable to stand due to weakness and pain in both legs. He had no symptoms of diarrhea, vomiting, rhinorrhea, or decreased sense of smell or taste. His medications include azithromycin and acetaminophen.

On the initial examination, he had a fever of $38.5^{\circ} \mathrm{C}$ and a respiratory rate of 18 . Oxygen saturation was 95 percent in room air. On clinical examination, mild crackles were heard at the base of both lungs. His chest computerized tomography scan revealed small ground-glass nodules, indicating viral pneumonia, scattered across the left lower lung.

His lab testing revealed marked lymphopenia (absolute lymphocyte count: 900), elevated C-reactive protein (CRP) (20 mg/L) (neg <3 mg/L), and marked elevation of creatine phosphokinase (CPK) at 8,000 units per liter (U/L) (range: 24-170 U/L). Lactate dehydrogenase was $500 \mathrm{U} / \mathrm{L}$ (normal range: 120-250 U/L). Liver function tests were normal 


\begin{tabular}{|c|c|c|c|}
\hline & 导 I & 0 & $\stackrel{\llcorner}{\Sigma}$ \\
\hline & 邑䓃 & 우 & $\approx$ \\
\hline & 点 & 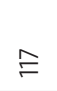 & $\stackrel{m}{m}$ \\
\hline & 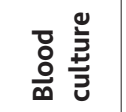 & $\frac{D^{\infty}}{2}$ & $\stackrel{\infty}{\stackrel{\infty}{z}}$ \\
\hline & 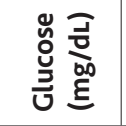 & ৪ & 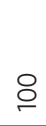 \\
\hline & 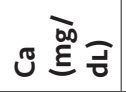 & $a$ & $a$ \\
\hline & ن & $\stackrel{\infty}{\infty}$ & $\stackrel{\sim}{\circ}$ \\
\hline & 志 离 & $\stackrel{\sigma}{\sigma}$ & $\simeq$ \\
\hline & $\times \begin{array}{r}\overline{\vec{J}} \\
\times \stackrel{\overrightarrow{\underline{E}}}{\xi}\end{array}$ & $\stackrel{\frac{\omega n}{\gamma}}{\sigma}$ & $\stackrel{\infty}{m}$ \\
\hline & 조 & $\hat{m}$ & $\stackrel{\stackrel{n}{m}}{\sim}$ \\
\hline & 을 & $\begin{array}{l}8 \\
8 \\
\infty\end{array}$ & $?$ \\
\hline & 宅 & ○ & $\sim$ \\
\hline & $\pm \stackrel{\widehat{\tilde{\xi}}}{\underline{\xi}}$ & 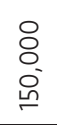 & $\begin{array}{l}\stackrel{8}{\circ} \\
\stackrel{+}{\infty} \\
\stackrel{\infty}{\sim}\end{array}$ \\
\hline & 오 & $m$ & $\underset{\searrow}{\stackrel{\infty}{\beth}}$ \\
\hline & 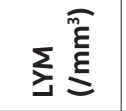 & ৪ & 离 \\
\hline 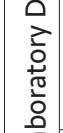 & $\sum_{\Delta}{ }_{0}^{\widetilde{\tilde{E}}}$ & 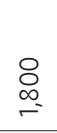 & $\underset{\square}{\stackrel{\circ}{\circ}}$ \\
\hline 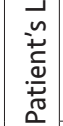 & 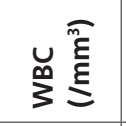 & 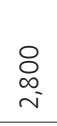 & D \\
\hline 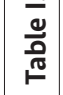 & 苂苞 & 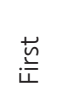 & $\underset{\Xi}{\Delta}$ \\
\hline
\end{tabular}

except for aspartate aminotransferase which was $117 \mathrm{U} / \mathrm{L}$ (normal range: $<37 \mathrm{U} / \mathrm{L}$ ).

His creatinine was 0.8 milligrams per deciliter $(\mathrm{mg} / \mathrm{dL})$, which was in the normal range. His urine test demonstrated the presence of blood on a urine dipstick test without any red blood cells (testing of the unspun urine was positive for "heme" on the dipstick, but the visual and microscopic examination of the sediment from the fresh urine specimen was negative for red blood cells (RBC) which suggested myoglobinuria). Renal Doppler and abdominal ultrasound scans were normal. His electrocardiogram was normal and no arrhythmia was observed. The toxicology screen was negative. The patient's COVID-19 polymerase chain reaction test performed via nasopharyngeal swab was positive. His flu test was negative. He was given a 20 $\mathrm{cc} / \mathrm{kg}$ normal saline bolus and started on isotonic intravenous fluids (at two times the maintenance rate) containing sodium bicarbonate. Fluids were titrated to achieve alkalinization of the urine with a goal urine $\mathrm{pH}$ of 8.0. The patient was prescribed hydroxychloroquine and azithromycin for five days. On hospital day 3 , his fever stopped and myalgia improved relatively. On hospital day 4, his CPK was 2,000 $\mathrm{U} / \mathrm{L}$ and his urine was negative for blood, so the fluid rate was decreased (Table I). Two days later, the patient was discharged as his clinical and laboratory symptoms had improved.

\section{Discussion}

Rhabdomyolysis is a life-threatening syndrome that is caused by the destruction of muscle cells for various reasons such as viral myositis, trauma, connective tissue disorders, pharmacological, and metabolic disorders $(3,4)$. Viral-associated rhabdomyolysis especially due to influenza is a common cause of rhabdomyolysis in pediatric patients (5).

Several hypotheses explain the mechanism of rhabdomyolysis due to viral causes. First of all, a direct attack of the virus on muscle cells can lead to rhabdomyolysis (6). The second reason is due to the immune system's response to the viruses, which leads to a cytokine storm and eventually muscle destruction. The third factor is the circulating toxins of viruses that directly affect muscle cell membranes (4). However, the mechanism of COVID-19induced rhabdomyolysis is not yet known.

Herein, we present a pediatric patient with severe rhabdomyolysis without renal involvement associated with COVID-19 infection. To our knowledge, only a few cases of COVID-19-associated rhabdomyolysis have been previously reported in children $(2,7)$. Gilpin et al. (8) presented a case of a 16-year-old adolescent with rhabdomyolysis as an initial presentation of COVID-19, Anwar and Al Lawati (9) presented a 16-year-old boy with COVID-19-induced rhabdomyolysis who eventually died, and Ashley M. Gefen also presented a 16-year-old boy with severe rhabdomyolysis without renal involvement which was related to COVID-19 infection (similar to our case) (2) (Table II).

Another cause of rhabdomyolysis is metabolic diseases. In the above patient, due to the negative family history, unrelated parents, and no history of recurrent cramps or exercise intolerance, the possibility of associated metabolic disease was ruled out (10). Muscle pain and weakness are common symptoms of COVID-19 (11). Myalgias have been observed in more than half of patients with COVID-19 infection. Elevated serum CPK levels indicate the severity of the disease ranging from mild to frank rhabdomyolysis (11). CPK levels should be measured in suspected patients (12). The first step in treating rhabdomyolysis is intense fluid therapy to maintain urine volume and prevent acute renal failure, an early correction of electrolyte disorders, and a correction of 


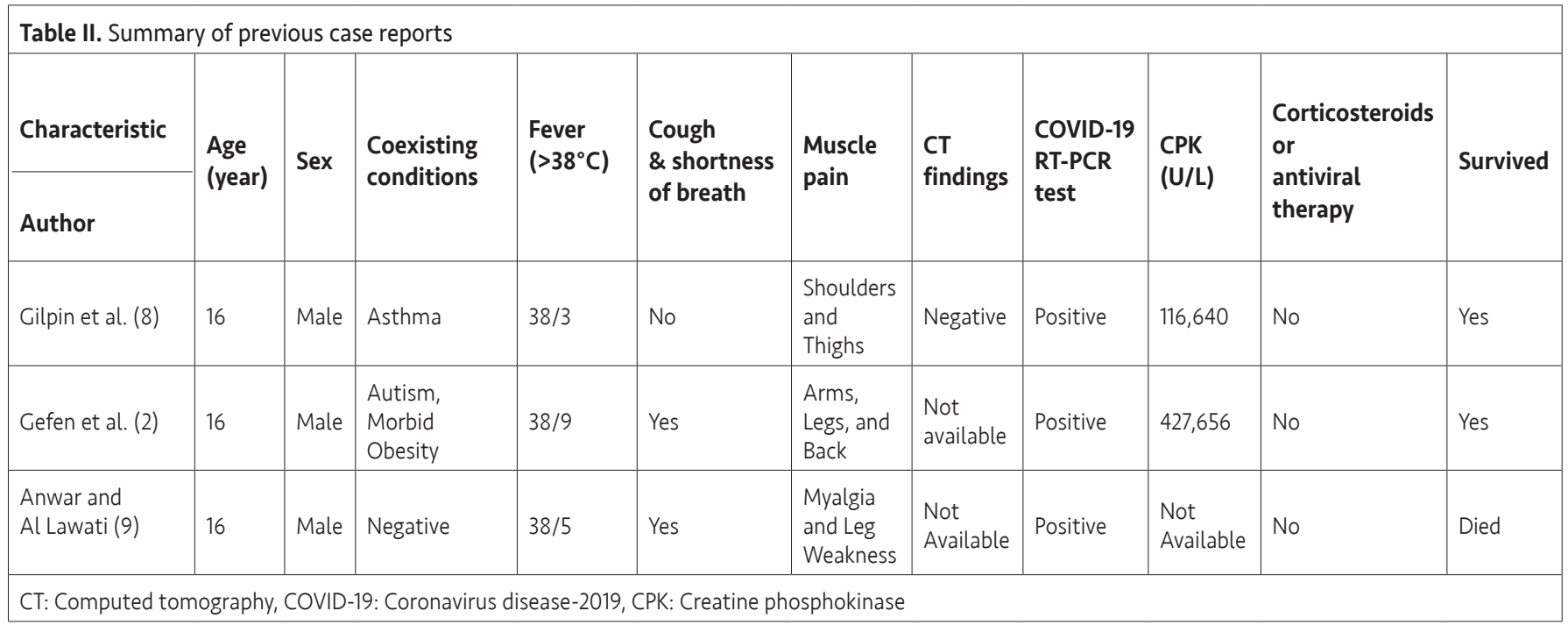

metabolic acidosis. Normal saline should be administered as soon as possible at the onset of muscle injury and continued until recovery. However, there is little clinical evidence for its effectiveness. Forced alkaline diuresis may be performed with bicarbonate administration to reduce the renal toxicity of heme (4). The best treatment and the amount and speed of bicarbonate administration are not well known (13). A large cohort study in adults showed the presence of rhabdomyolysis was associated with increased mortality (14). Therefore, the prompt diagnosis and timely treatment of rhabdomyolysis help to reduce complications of those patients with COVID-19.

\section{Conclusion}

Rhabdomyolysis can be the first symptom of COVID-19 or it can occur at any time during the course of the disease. Pediatric physicians should be aware of this complication. Timely diagnosis and proper treatment improve the patient's prognosis.

\section{Ethics}

Informed Consent: All participants gave written informed consent.

Peer-review: Externally peer-reviewed.

\section{Authorship Contributions}

Concept: Pari.A., P.A., Design: Pari.A., P.A., Data Collection or Processing: Pari.A., P.A., Analysis or Interpretation: Pari.A., P.A., Literature Search: Pari.A., P.A., Writing: Pari.A., P.A.

Conflict of Interest: No conflict of interest was declared by the authors.
Financial Disclosure: The authors declared that this study received no financial support.

\section{References}

1. Guan W], Ni ZY, Hu Y, et al. Clinical characteristics of coronavirus disease 2019 in China. N Eng I Med 2020; 382:1708-20.

2. Gefen AM, Palumbo N, Nathan SK, Singer PS, Castellanos-Reyes L), Sethna CB. Pediatric COVID-19-associated rhabdomyolysis: a case report. Pediatric Nephrology (Berlin, Germany). 2020 May 23:1.

3. Al-Ismaili Z, Piccioni M, Zappitelli M. Rhabdomyolysis: pathogenesis of renal injury and management. Pediatr Nephrol 2011; 26:1781-8.

4. Moniz MS, Mascarenhas MI, Escobar C, et al. Rhabdomyolysis as a manifestation of a metabolic disease: a case report. Rev Bras Ter Intensiva 2017; 29:111-4.

5. Mannix R, Tan ML, Wright R, Baskin M. Acute pediatric rhabdomyolysis: causes and rates of renal failure. Pediatrics 2006; 118:2119-25.

6. Fadila MF, Wool KJ. Rhabdomyolysis secondary to influenza a infection: a case report and review of the literature. N Am J Med Sci 2015; 7:122-4.

7. Qiu H, Wu J, Hong L, Luo Y, Song Q, Chen D. Clinical and epidemiological features of 36 children with coronavirus disease 2019 (COVID-19) in Zhejiang, China: an observational cohort study. Lancet Infect Dis 2020; 20:689-96.

8. Gilpin S, Byers M, Byrd A, et al. Rhabdomyolysis as the initial presentation of SARS-CoV-2 in an Adolescent. Pediatrics 2021; 147:e2020019273.

9. Anwar H, Al Lawati A. Adolescent COVID-19-associated fatal rhabdomyolysis. I Prim Care Community Health 2020; 11:2150132720985641

10. Miller ML. Clinical manifestations and diagnosis of rhabdomyolysis. Up Todate, Version. 2014 and 11. Available from: https://www.uptodate.com/contents/clinical-manifestationsand-diagnosis-of-rhabdomyolysis 
11. Disser NP, De Micheli A), Schonk MM, et al. Musculoskeletal consequences of COVID-19. J Bone Joint Surg Am 2020; 102:1197204.

12. Suwanwongse K, Shabarek N. Rhabdomyolysis as a presentation of 2019 novel coronavirus disease. Cureus. 2020 Apr and 12(4).

13. Inc, Palevsky PM. Prevention and treatment of heme pigmentinduced acute kidney injury (acute renal failure) Uptdate and http://www.uptodate.com/contents/prevention-andtreatment-of-heme-pigment-, c2017. [2015 Nov 16]. Last Accessed Date: 21. 09.2021. Available from: [Internet] Available from:

14. Geng $\mathrm{Y}, \mathrm{Ma} \mathrm{Q}, \mathrm{Du} \mathrm{YS}$, et al. Rhabdomyolysis is associated with in-hospital mortality in patients with COVID-19. Shock. Jan 13. doi: 10.1097/SHK.0000000000001725. Online ahead of print. 